\title{
Caring for Older Persons in a Technologically Advanced Nursing Future
}

\author{
Joseph Andrew Pepito',2, Rozzano C. Locsin ${ }^{3,4}$, Rose E. Constantino ${ }^{5}$ \\ ${ }^{1}$ Cebu Doctors' University, Cebu City, Philippines \\ ${ }^{2}$ University of the Visayas, Cebu City, Philippines \\ ${ }^{3}$ Tokushima University, Tokushima, Japan \\ ${ }^{4}$ Florida Atlantic University, Boca Raton, FL, USA \\ ${ }^{5}$ Department of Health and Community Systems, School of Nursing, University of Pittsburgh, Pittsburgh, USA \\ Email: pepitojosephandrew@gmail.com
}

How to cite this paper: Pepito, J.A., Locsin, R.C. and Constantino, R.E. (2019) Caring for Older Persons in a Technologically Advanced Nursing Future. Health, 11, 439-463.

https://doi.org/10.4236/health.2019.115039

Received: April 18, 2019

Accepted: May 11, 2019

Published: May 14, 2019

Copyright () 2019 by author(s) and Scientific Research Publishing Inc. This work is licensed under the Creative Commons Attribution-NonCommercial International License (CC BY-NC 4.0).

http://creativecommons.org/licenses/by-nc/4.0/

\begin{abstract}
As people live longer, a larger percentage will live with multiple chronic conditions and functional impairments such as difficulties with activities of daily living, mobility, and the management of one's household. The purpose of this paper is to examine the care of older persons in a technologically advanced nursing future by discussing roles and responsibilities of nurses who practice gerontological nursing, and explaining how a technologically advanced future would change the delivery of home health care for older persons in the community. The theory of Technological Competency as Caring in Nursing grounds 3 processes of nursing as knowing persons as caring, wholeness is oneness, and caring as a multi-dimensional process. Harnessing technology for the health of older persons would enable them to live independently, socially engaged, and safely. A technologically advanced nursing future leads to concomitant sustainable disruptive and frugal innovations in healthcare. Nurses in practice must take advantage of these disruptions and consider frugal innovations as the futures of nursing education, practice, and research are here.
\end{abstract}

\section{Keywords}

Big Data, Competency, Gerontology, Nursing, Older Persons,

Technologically Advanced Nursing Future

\section{Introduction}

The world is experiencing a dramatic sociodemographic shift. From 2015 to 2050 , the proportion of the world's population that is over 60 years old will be 
nearly double (from $12 \%-22 \%$ ). By the year 2020, people aged 60 years and older will outnumber children younger than 5 years old [1]. All nations face considerable challenges to cope with this shift in demographics.

As people live longer, a larger percentage will live with multiple chronic conditions such as diabetes, hypertension, or dementia [2] and functional impairments such as difficulties with activities of daily living, mobility, and the management of one's household [3]. One of the most difficult health care challenges the world is facing is ensuring that older persons with chronic illnesses continue to be independent as long as possible. As older persons experience the aging process, healthcare providers are needed to assist in achieving the best quality of life.

Admission episodes for people in the 65 - 84 age group have seen the greatest increase in volume across the last ten year period. The admission episodes rose from over 2 million episodes in 2006-2007 to 6.3 million in 2016-2017. In contrast, episodes from the 15 - 44 age group only increased from 300,000 to 4.7 million in the same period [4]. Gerontologic Nursing has become a very relevant specialty in nursing in addressing future problems caused by the rapid graying of the population.

About $50 \%$ of WHO Member States have reported having less than 3 nursing and midwifery personnel and about $25 \%$ reported having less than 1 nursing and midwifery personnel per 1000 population in 2018 [5]. Experts say that the nursing workforce is not sufficiently prepared for the number of older persons who are living longer, and sicker, with more chronic and complex health conditions [6]. To address the problem of the nursing shortage, the American Organization of Nurse Executives (AONE) made specific recommendations to examine the use of technology to improve the capacity of a reduced nursing workforce [7].

\section{Purpose}

The purpose of this paper is to examine the care of older persons in a technologically advanced nursing future by discussing roles and responsibilities of nurses who practice gerontological nursing, and explaining how a technologically advanced future would change the delivery of home health care for older persons in the community.

The unstoppable growth of the population of older persons globally will significantly impact the reshaping of contemporary nursing care patterns. Solutions to the challenges of providing effective healthcare to a growing number of older persons are developed but rarely tested. Therefore, we suggest that research is needed to examine the role of technology in the care of older persons in a technologically advanced future.

\section{Nursing in a Technologically Advanced Future}

Older persons with fragile health often need specialized care as minor health-related issues oftentimes rapidly spin out of control if unattended or untreated. A ge- 
rontological nurse is a type of nurse who specializes in the care of older persons, undergoes specialized training in assessing the unique needs of older persons. This specialized training enables them to care for older persons with competence and evidence-based practice [8].

Technological breakthroughs occur at an ever-increasing pace [9], thereby revolutionizing wellbeing and health care [10]. Technological advancements have drastically changed the structure and organization of nursing [11] so much so that the modal changes in modern healthcare have transformed nursing's delivery of care. Healthcare technology serves as tools and guideposts for caring [12]. As nurses integrate emerging technologies in their practice, nurses need to consider technological advancement as promising solutions to meeting the healthcare needs of older persons [13].

In a technologically-advanced future, person-centered care is a timely conceptual framework to base healthcare systems' infrastructure [14]. In person-centered care, the nurse and the patient collaborate in managing the healthcare needs of the patient. Person-centered care in nursing focuses on the person's individual needs, desires, and goals so that they are considered as the central concepts in nursing practice [15]. The person's needs, for example, as defined by the patient are clearly prioritized, and performed above those that have been identified by healthcare professionals. Person-centered care puts more importance on the health experiences of patients concerning their health, illness, freedom, injury, need, and safety [16]. The patient and nurse become central figures to influence patient-centered care.

\section{The Theory of Technological Competency as Caring in Nursing}

The theory of technological competency as caring in nursing provides the perspective through which nursing care is expressed with the patient as the central focus. The theory is derived from the general concept of Nursing as Caring [17]. Technological Competency as Caring in Nursing is a middle range theory that illustrates nursing practice with technological competency is expressed as caring. Its key conceptual tenet is based on the coexistence among technology, caring, and nursing as a discipline of knowledge and as a practice profession.

The legitimacy of the theory is supported by five assumptions. First, persons as caring by virtue of their humanness. This assumption accentuates the expression of caring as beneficial to all persons who care, although their expression of caring can vary. This realization is crucial in the appreciation of the fullness of the value of human beings as always caring persons, 2) second, the idea of wholeness is a perspective of oneness. The idea of wholeness provides the recognition of human beings as always complete in their being, without referencing its composition of parts [18]. This allows the nurse to focus on nursing as a lived experience that is shared between the nurse and the patient [17].

The third assumption focuses on knowing persons as caring is a multidimen- 
sional process [19] in which the patient and the nurse, concentrate on celebrating, appreciating, affirming, and supporting each other as caring persons while permitting the mutual recognition of the meaningfulness of their being as dynamic participants in human caring. The fourth assumption is that health and nursing technologies are elements for caring [19]. Through the use of technologies, nurses in practice would be capable of knowing human beings more fully as persons who are active contributors in their care rather than simply objects of care. Lastly, nursing is a discipline of knowledge and a practice profession [19]. As a profession and a discipline, paramount to its existence is knowledge development. Advances in the practice of nursing are concentrated on enhancing its legitimate contribution with regard to healthcare, in which the practice of nursing is a significant element to the attainment and maintenance of human wellbeing and health.

\section{Knowing Persons as a Process of Nursing}

The theory of Technological Competency as Caring in Nursing [19] grounds three processes of nursing as "knowing persons as caring". It unfolds as technological knowing, mutual designing and participative engaging. Technological knowing is the utilization of technologies for the purpose of knowing persons more fully as caring persons. With technological knowing, health care technologies and being experts in these technological advances are greatly recognized as essential to the practice of nursing.

Possessing this information about the patient allows the nursing encounter (engagement) between the nursed and the nurse in order to know the person more fully as a person. Mutual designing emphasizes the valuing of persons as collaborators in their care rather than being objects of care or human bodies containing diseased organs. With the nursing encounter that is mutually designed, participative engaging occurs so that both the caregiver and the cared for, are able to live their lives more meaningfully as caring persons with hopes, dreams, and aspirations.

Therefore, person-centered care in nursing is guided by the process of "knowing persons as caring in nursing". The theory of Technological Competency as Caring in Nursing can be implemented at the participative level, focused on the person being nursed as always whole, and complete rather than on fixing the person or completing or replacing the person's missing parts [13].

\section{Technologies in Older Persons' Care}

Advances in technology enable nurses to perform their activities and care for patients more safely and efficiently. There is a host of healthcare technologies today that monitor the status of the patient, new ways of documentation like the electronic health record, and the use of telehealth technologies that enable patients to receive care in their preferred locations are some instances of technological advances changing the way nursing is being practiced today. 
Consequently, nursing today isn't the same as it was 30 or so years ago. Similarly, gerontologic nursing today isn't the same as it was 30 years ago as well. "Gerontechnology" [20] began in the late 1990s when gerontologists and technology experts met and discussed the design and development of technologies that support demands and concerns of older persons. The goal was to improve life satisfaction of older persons with or through the use of technology.

Technology is a tool to fast-track the three aims of healthcare, to 1) improve the experience of patients to care, 2) improve the health of the populations, and 3 ) reduce the cost of health care per capita [21]. The American Geriatrics Society Expert Panel on person-centered care [22] suggests that the continuous sharing of information and integrated communication is essential to the achievement of person-centered care. This integration and sharing can be completed through technological means [23]. Technology has also been considered as the solution to workforce shortages, home management of complex chronic illnesses, and the omnipresent health equity issues such as rural and urban access to health care can be addressed through technology.

Harnessing technology for the health of older persons would enable them to live independently and safely. Technological inventions such as devices that enable older persons to connect with family and friends like GrandPad [24], a simplified computer/tablet, smartphones and video chats like Skype or FaceTime [25] [26]; and medication management devices like medication reminders [27], pill dispensers [28]; or telehealth systems that monitor blood pressure, pulse, blood glucose, and more [28]; and devices that promote exercise and fitness activities like the Wii Fit Plus [29]; or games that encourage seniors to participate in cognitive activities, altogether declare the technological dependency of older person for care today. Technology has also made it possible for older persons to live alone safely through home monitoring systems [30], Personal Emergency Response Systems [31], and GPS tracking systems that prevent wandering among patients with dementia [32].

Gerontologic nurses of the future need to integrate emerging technologies in their practice, education, and research. To ensure that the technology would be responsive to the needs of older persons, nurses need to be involved in its development [13]. For nurses to remain relevant in a technologically advanced future, nurses need to ensure the evidence-based delivery of care through the use of technologies. Gerontologic nurses of the future will be overseers of care [13], delegating tasks to intelligent machines like the monitoring of vital signs, checking of blood sugar levels, the incidence of pressure ulcers, or the risk for falls. Using these technologies in the care of older persons will be a mandate of nursing care.

\subsection{Home Health Care}

Home Health Care is a system of care for home-bound patients that are provided by skilled health care practitioners under the direction and supervision of a healthcare professional. Nursing care is included in home health care ser- 
vices. The goals of home health care services are to 1) assist persons to improve their level of functioning and live with greater independence, 2) promote an optimal level of well-being and, 3) prepare the patient to remain in their respective homes and avoid hospitalization, admission, or readmission to institutions for long term care [33] [34] [35]. Rosati [36] identified six advantages to home-based care, they are: 1) enhanced view of patients and caregivers that would lead to better comprehension of important issues, like how they manage nutrition and medications; 2) enhanced access to health care that is very relevant to patients with physical and socioeconomic barriers to health care; 3) a more collaborative clinician-patient relationship; 4) an expression of the act of humility by stepping out of their comfort zones to be with the patient and that the patient and the patient's family are worthy of being known and visited; 5) desired services are made available to patients at lower costs; and 6) a greater safety for frail elders, due to fewer common complications of hospitalizations like nosocomial infections.

Han, Kim, Storfjell, \& Kim [37] found that home health care services had an effect on clinical outcomes including activities of daily living, instrumental activities of daily living, quality of life of patients, functional status, and functional capacity. Functional status is an important ingredient in independent living and the improvement of the quality of life while functional capacity is key for home health care in the maintenance of the ability of older persons to live independently and safely at home [38]. It has also been noted by Roy and others (2018) that the majority of older persons prefer to remain in their homes for as long as possible [39]. Because of the advantages of home health care services, the home and the community in the future will emerge as the primary settings for a diverse consortium of health care services [34]. Homes and health services will be synonymous that it would not be referred to as home care but as "modern healthcare" [36].

\subsection{Technology in Modern Healthcare}

Technology in modern healthcare fosters and engenders community-based independence. Technologies such as electronic health records [40], mobile-assisted devices [41], biofeedback systems monitor a patient's involuntary body functions like temperature, blood pressure, blood sugar, and heart rate, thereby preventing the occurrence of conditions like high blood pressure, fever, hyperglycemia or hypoglycemia [42], and alarm integration technology [43]. While caregivers play the most significant role in keeping older persons healthy at home, technology for modern healthcare provides the tools essential to enable cost-effective healthcare. Telehealth including remote monitoring will be a crucial factor in modern healthcare as it uses advanced technologies that support long-distance care for patients [44]. Home health remote monitoring or telehealth gives the caregiver the ability to screen, measure, and monitor the patient's health condition from a dis- 
tance [45]. These systems can record and monitor a wide range of items such as an electrocardiogram (ECG), vital signs, blood glucose, pulse oximetry, and weight [46]. Data from a variety of chronic diseases such as congestive heart failure, diabetes, asthma, and hypertension can also be collected from patients [45].

Technology also allows healthcare professionals to remotely communicate with their patients, make changes on their care plans and interventions on a real-time basis, and monitor the patients' physical response to those changes [47]. Studies have shown the effect of remote monitoring on reducing readmissions for older persons with chronic heart failure and reduced number of nursing visits per week for those with diabetes [48] [49]. The healthcare system is currently facing a multitude of challenges such as increasing healthcare services needed by older persons, a grave healthcare provider shortage, tightening of state and federal budgets, and insurance limits. The use of telehealth/remote monitoring systems would play a crucial role in the provision of access and continuity of care for the older persons, enabling them to stay at home as long as possible [46]. Furthermore, telehealth could be a solution to addressing the problem of nursing shortage around the world [50]

\subsection{Other Technologies Revolutionizing Home Health Care for the Older Persons}

\subsubsection{Mobile Devices}

A technology that can support older persons' healthcare are mobile devices. As a person ages, there is an increasing likelihood of having multiple health problems and this leads to an increasing need for health and/or disease management interventions [51]. A systematic review by Whitehead and Seaton [52] found evidence indicating the potential of applications in improving the management of symptoms through self-management interventions. They have also concluded that the use of mobile device applications has the potential for health outcome improvement among those living with chronic conditions through enhanced symptom control. There are a number of applications in smartphones that have been developed specifically for older persons (Table 1) and further optimization, innovation, and rigorous research around the potential of mobile device applications will move the technology toward the reality of improved health care delivery and outcomes.

\subsubsection{The Internet-of-Things}

The Internet-of-Things (IoT) is a network of devices that are embedded with electronics, sensors, software, and network connectivity and this enables these devices to collect and exchange data [65]. Several definitions of IoT can be taken from different perspectives. From the viewpoint of services provided by devices, IoT means a reality where devices can automatically communicate with computers and with other devices that provide services that humankind can benefit from [66]. From the viewpoint of connectivity, IoT means anyone has 
Table 1. Examples of smartphone applications for older persons.

\begin{tabular}{lll}
\hline Category & Mobile Application & \\
\hline & & Use \\
\hline & & iGeriatrics is a composite of all the American Geriatrics Society's clinical information \\
& into one easy to use application. Included is information from the following titles: \\
Disease diagnosis or & - Geriatrics Cultural Navigator \\
management & iGeriatrics & Guide to common immunizations \\
& - Prevention of Falls Guidelines \\
& - AGS Beers Criteria \\
& - GeriPsych Consult \\
& - Management of Atrial Fibrillations [53]
\end{tabular}

MICROMEDEX

(IOS and Android)

Medscape

Treatment and

Medication

MIMS

Lexicomp

Epocrates

uHear (IOS)

Applicationsfor

hearing loss

hearScreen

(Android)
AngelSense

Disease

Dementia Screener

(Android)

Parkinson's LifeKit

(IOS)

Applications for

Parkinson's Disease
MICROMEDEX is a collection of several databases for drugs which includes Martindale, DRUGDEX, POISONDEX, DISEASEDEX, the Physician's Desk Reference (PDR) and a host of other alternative healthcare databases. Medications can be searched by generic name, trade name, or even "street" name [54].

The Medscape application provides accurate and fast clinical answers at the point of care and is the number one medical resource for physicians, nurses, medical students, and a host of other healthcare professionals [55].

The MIMS application is built with an intuitive, multi-concept search engine that is connected to the comprehensive MIMS Drug Database and is equipped with complete educational resources to aid healthcare professionals in making informed clinical decisions [56].

The Lexicomp Mobile Application offers an extensive online drug reference where users can access more than 20 drug databases, featuring timely, in-depth information on natural products, drugs, drug interactions, medical calculations and more [57].

Epocrates application provides clinical reference information on drugs, diagnostics, diseases, and management of patients [58].

The uHear application is a self-administered screening tool for the identification of hearing impairment [59].

The uhear Screen application is a smartphone hearing screening that is accurate, cost-effective, and clinically-validated [60].

The AngelSense device is attached to the clothing of a loved one and provides monitoring of a loved one's location, routes, and transit speeds and sends an instant alert to the smartphone of the caregiver if the loved one is in an unfamiliar place. Also gives caregivers the ability to listen to what is happening around their loved one, can receive alerts if their loved one is missing an appointment and also allows caregivers to communicate with their loved one. The device also has a GPS tracking system so an alarm can be sent to caregivers to locate their loved ones [61].

Dementia Screener application diagnoses if someone has symptoms of dementia. It is used for the detection of early symptoms of Alzheimer's disease [62].

Parkinson's LifeKit application tracks symptoms of Parkinson's and finds patterns over time. The application tracks daily physical movement, emotional state, cognitive function, and medication phases. It also provides a detailed log of the medication regimen, set reminder alerts for activities and medication, and creates reports for the healthcare professional [63].

The MyTherapy application tracks symptoms of Parkinson's disease over time. The application also has a medication reminder and has a highly customizable scheduler for reminders. The application is also capable of keeping a Parkinson's journal that documents medication taken, the evolution of Parkinson's symptoms, and state of health. The application also visualizes measurements, medications, and symptoms in a PDF health report that can be shared with healthcare professionals. The application also reminds the user about his/her next appointment and it also manages medications and alerts the user on the number of Parkinson's medication available [64]. 
connectivity anytime or anyplace and will now have connectivity to anything [67]. From the viewpoint of communications, IoT refers to a network of interconnected devices uniquely addressable and are based on standard communication protocols that span worldwide [68]. And, from the viewpoint of networking, IoT is the evolved form of the Internet from a network of interconnected computers to a network of interconnected devices [69]. The recent developments in IoT technology can play a significant role in the design of a suitable healthcare system for older persons. Smart homes can revolutionize the method in which healthcare services are being provided to older persons by integrating health and other ambient assisted living technologies [70].

\section{1) IoT Devices that Promote Medication Adherence}

Studies have shown [71] that if patients are aware that their treatment habits are being monitored, adherence improves by 20 percent. IoT is able to take it further-beyond just notifying the patients of their status in adherence, connected device technologies can provide an end-to-end medical solution. An example is smart packaging. Sensors in a connected medication package can transmit information about the time a package is opened, which will be transmitted through a secure network and onto a platform for management that allows monitoring [72].

Devices such as the Sensemedic [73], is capable of "smart dispensing". A smart dispenser is capable of audibly or visually alerting a patient that they need to take their medication. The dispenser is tamperproof or lockable to avoid overdosing. Adherence of each patient can be accurately determined and this allows healthcare professionals to implement measures that can guide and support patients better: working from the existing behavior towards an improved intake pattern [74].

\section{2) IoT Enabled Wearable Healthcare Devices}

IoT enabled wearable healthcare devices allow for remote monitoring of different vital signs and states of health and allow healthcare providers to stay connected with their patients and to gain better visibility into their health [75]. The biggest benefit of IoT-enabled wearable healthcare devices is the provision of information to individuals that can give them better control over their health outcomes. Individuals can monitor different factors of fitness, health, wellness and track progress towards health goals. IoT enabled wearable healthcare devices also enable those with conditions that need close monitoring to track important health indicators on a day-to-day basis. The data collected can be shared with healthcare providers for a more detailed understanding of the condition. It is also capable of updating in real-time electronic health records through cloud-based accessibility [75].

The growing accuracy of IoT enabled wearable healthcare devices would benefit healthcare providers more because care plans can be formulated through the evaluation of data recorded in the devices [76]. IoT enabled wearable healthcare devices are improving self-management abilities and are also becoming key diagnostic instruments for healthcare providers. Recorded data from such devices 
are wirelessly transmitted, and the healthcare provider can assess important statuses without having to schedule an appointment [77].

\subsubsection{IoT Enabled Smart Homes}

A smart home that is integrated with assisted living technology and e-health can potentially play a crucial role in revolutionizing the healthcare system for older persons [70]. In a smart home, actuators and sensors are connected via a Personal Area Network (PAN) or Wireless Sensor Network (WSN). Wearable healthcare devices such as electrocardiogram (ECG), electromyogram (EMG), electroencephalogram (EEG), oxygen saturation and body temperature devices can be connected in a Wireless Body Area Network (WBAN) or Body Sensor Network (BSN) for obtaining continuous, automated, and real-time measurement of physiologic statuses [70].

The central computing system collects environmental, activity, and physiological data for analysis and sends feedback to the user or trigger activation of actuators to control appliances such as oxygen generator, air conditioner, humidifier, or even the oven. It also functions as the central home gateway that is capable of sending measured data to healthcare providers over the internet. An IoT enabled smart home is also capable of automated emergency call systems which enable the older persons to communicate with healthcare providers in cases of emergencies. Smart homes are also equipped with automated activity and fall detection systems that compare normal and abnormal activities in order to respond appropriately through the use of video-based systems [70].

Frequent and immediate medical intervention may be required by older persons. Such emergency situations can be avoided by constant monitoring of the physiological status and activities of the older persons. Remote health monitoring in a smart home platform allows the older persons to remain in a comfortable home environment rather than in nursing homes that are expensive and limiting or hospitals [78]. Smart homes also ensure maximum independence to occupants [79].

\subsubsection{Big Data Analytics}

The recent and rapid increase in digital data generation and the rapid development of computational science has enabled the extraction of new insights from massive data sets known as "big data". Data whose scale, diversity and complexity require new architecture, algorithms, techniques, and analytics to manage and extract value and hidden knowledge from it is known as "big data" [80]. Big data analytics utilizes the various algorithms of data mining. Data mining is the automatic extraction of useful and previously unknown information from huge databases or datasets utilizing advanced search techniques and algorithms for the discovery of patterns and correlations in large pre-existing databases [81].

The three drivers of the era of big data are to improve healthcare quality and patient outcomes, increasing the availability of data, and increasing capabilities 
in the analysis [82]. The potential value of big data analytics are: 1) the delivery of therapies that are personalized; 2) the use of clinical decision support systems such as the mining of literature in medicine; 3) personalized diagnostic and treatment decisions and educational messages to support desired behaviors of patients through the use of mobile devices; 4) big data-driven health analyses of populations revealing new patterns in health data; and 5) fraud prevention and detection [83].

In older persons care in a technologically advanced future, there are a number of methods in which data is being collected including electronic health records, social media, mobile health applications, health surveys, wearable health devices, various medical devices, and remote monitoring systems [84]. For seniors, the optimized collection and use of available data can make a significant difference in meeting health care's Triple Aim of improving the health of populations, enhancement of the experience of care, and reducing costs [85].

Optimal use of big data from seniors can help improve health outcomes in many ways. The use of predictive models and evidence-based care that can be achieved through clinical analytics may enable support for earlier intervention for individuals who may be at more risk to rapid decline [86]. Furthermore, because the older person population is especially vulnerable to healthcare-acquired infections and chronic conditions, making it possible to receive care at home with the support of remote monitoring makes the use of big data an attractive alternative-in addition to improving quality of life [87]. And finally, seniors who experience especially high rates of chronic disease, which are very responsive to frequent or continuous remote monitoring of specific data points that can inform early diagnosis and treatment can also help limit disease progression and recurrent hospitalizations [88].

\subsubsection{Robots for Older-Persons' Care}

Although we are still a long way from the imagined future in the movie "Robot and Frank" where robots are capable of almost everything humans can do, studies have shown [89] [90] [91] [92] that autonomous robots that are programmed to interact and communicate with humans could address issues of social interaction and care. These robotic technologies are believed to reduce loneliness and increase the independence of the elderly.

A substantial increase in the older person population results in a number of issues in healthcare such as the inadequacy of healthcare professionals, centers, and services [93] and huge burdens of costs in healthcare [94]. In order to decrease the costs related to transportation and readmissions, and also to improve the quality of health-care services and the independence of the older persons, healthcare services are shifted to the homes of the older persons from medical institutions [95].

This necessitates the creation of different types of assistive medical robots (Table 2) to fulfill the various needs of the older persons and compensation of disabilities [96]. Studies have shown that assistive medical robots also improved 
Table 2. Examples of robots for the care of older persons.

\begin{tabular}{cl}
\hline Robot's Name & \multicolumn{1}{c}{ Description } \\
\hline Robear & $\begin{array}{l}\text { A nursing care robot that performs tasks such as assisting the older persons in standing up, or lifting them from a bed into } \\
\text { a wheelchair [102]. }\end{array}$ \\
& $\begin{array}{l}\text { A humanoid robot that can be used in nursing care for older persons with the ability to read and respond to human } \\
\text { emotions and this enables it to have conversations with older persons. Pepper's capabilities can be added through } \\
\text { personalization and will include: independent movement; assisting the older persons in everyday tasks like keeping track } \\
\text { of bills, assistance in to-do lists; providing health-related assistance like medication reminders, physical exercise, or } \\
\text { emergency alarm; providing easy access to technology like access to the internet, smart appliances for home automation, } \\
\text { video calls; and providing entertainment like playing music, videos, games, and reading [103] [104]. }\end{array}$
\end{tabular}

A general purpose service robot that has been given the ability to adapt to different situations, environments, and requirements. The design enables the robot to configure with the situation and is able to create a positive emotional bond on all three levels (behavioral, visceral, and reflective) with necessary social cues provided. The Care-O-bot 4 may be deployed in a variety of environments from home setting to medical assistants and can assume different roles [105].

Stands for Advanced Step in Innovative Mobility, is a humanoid robot that is capable of independent walking and stair climbing. It can also understand preprogrammed gestures and spoken commands, interface with IC communication cards, and recognize voice and faces. ASIMO's arms and hands give it the capability of doing things like turning on light switches, carry objects, open doors, and push carts. ASIMO has been designed to help those in a society that needs assistance like older persons [106] [107].

An elder care robot designed to assist older persons. It can keep a record of an older persons' medication and also reminds them when to take them, it also tracks their health and automatically answers calls family or healthcare professionals. It is also capable of setting up a video chat with the family or with healthcare professionals. It is also equipped with a karaoke feature with the purpose of amusing and entertaining the older persons [108].

A companion robot. It is a smart voice assistant integrated with a personality that can help in reminding the older ElliQ persons with their upcoming calendar appointments, display pictures from family, receive and send messages, play music and videos. It is equipped with a swiveling head and removable tablet and cameras. It is also capable of responding to requests. It can be asked to play games or tell jokes. It can also be asked to suggest activities [109] [110].

A companion robot. It is emotionally engaging through the cute and dog- inspired looks and is capable of showing emotion through the display of different colors in the shell part of its body. It is equipped with impressive optical navigating skills, a host of smart sensors for the detection of its surroundings and to tell when it is being stroked or patted, face recognition technology, medication reminders, monitor vital signs, calls for an emergency during cases of falling and more. It is envisioned as a tool that could one day play an essential role in the company for older persons. With the correct programming, MiRo will be able to engage emotionally with older persons. It would be able to provide amusement and companionship while the older persons are alone which alleviates isolation and encourages the older persons to look after themselves [111] [112] [113] [114].

A companion robot that is modeled after a baby harp seal. It is covered with soft artificial fur to mimic the feeling of touching a real animal and is also antibacterial. It has a diurnal rhythm of the morning, daytime, and night (it gets active during the day and less active at night). It is equipped with 5 different kinds of sensors for the perception of people and the environment: light, posture sensors, tactile, temperature, and audition. It is administered to patients in environments such as hospitals and extended care facilities and allows the documented benefits of animal therapy. It has been found to be effective in reducing stress in patients and their caregivers, it is capable of stimulating interaction between patients and caregivers, it improves the relaxation and motivation of patients, it is also capable of improving the socialization of patients with other patients and caregivers. PARO can be programmed to user preferences and respond to its new name. It responds as if it is alive by moving its head and legs, showing preferred behavior, and making sounds [115] [116] [117].

Resyone An electric bed embedded with a section that can be separated and converted into a reclining wheelchair that runs on electricity. It is able to help the older persons get out of bed [118] [119].

A one-hand assistive robot that provides easy-to-understand feedback with the use of video and audio which allows users to visualize on the spot the practice records and contributes to the increase of their motivations towards

TREE rehabilitation. This assistive robot also accompanies users during walking rehabilitation. It records and manages data during practice that enable users to review the progress in every training session. It measures foot pressure, checks on the load on each foot on a real-time basis to provide a comfortable training experience [120]]. 
A humanized, highly interactive social robot that has a range of capabilities that makes it the ideal companion in a home. It is capable of many social interactions using cues that are natural, emotive, and social for better understanding which establishes Jibo as more socially acceptable. It is capable of: telling interactive stories using movement, sound, and animation; it can recognize and track the faces of members of the family; it can accept voice commands from anywhere in a home; is able to detect natural cues like speech, movement, and smile to know when a person is posing for a picture; it can set reminders; send messages to the correct people at the correct time and place, text and voice messages are brought to life with expression packs; and video chat and telepresence with a camera capable of see-and-track makes it easy to turn and look at people through Jibo [121].

An automaton that performs functions ranging from reminders for medication, light conversation, staging video calls with family members. Is equipped with three wheels with a face comprised of a screen which can host pictorial prompters Stevie for those with impairments in hearing and can also be used to independently contact services for an emergency if the user becomes unresponsive. It is used to minimize risks such as falling, errors in medication, or carbon monoxide poisoning [122].

A companion robot that is capable of expressing a range of emotions throughout the day based on interactions with users. It has a range of capabilities such as monitoring for security, fire detection, and sends alerts for unusual situations; hands free control of connected devices in a smart home; it is a mobile telepresence robot; shares photos and videos;

Buddy connects to social networks; it has a memo, timer, reminder, and provides practical info like weather, news, and definition; it is also a moving interactive jukebox capable of taking photos and video calls; is capable of interactive games, mathematics, memory exercises, and introduction to programming; and can be personalized by downloading applications and adding new accessories [123].

A healthcare service robot equipped with a face, head, arm, and four wheels that is capable of a host of activities like grab and store medical supplies and deliver them to healthcare providers or patients. It uses sensors and artificial intelligence to enable it to learn about its environment and avoid obstacles. The screen displays information related to the tasks it is currently executing [124] [125].

the older person's quality of life and maintained their independence [97] [98] [99] [100] [101].

Using robots in the delivery of nursing care to older persons effectively aids in the under-staffed healthcare system [91]. A nursing robot system that has been designed specifically for the older persons may be able to carry out tasks that help the older persons like doing household chores and may be programmed to administer medical treatment to the older persons [126]. Use of robots may also lower the costs of healthcare services by lowering the cost of human labor [127]. Use of robots for transcription and storage of medical information with a minimized possibility for error helps healthcare providers in the care of the older persons [127].

Robots aid older persons to remain independent by reducing the need for human carers and institutionalization in professional care homes. Robots can remind the older persons when to eat, drink, or take their medication, perform exercises, or attend an appointment. And lastly, robots are very useful in continuous data collection and monitoring of older persons with the data relayed to healthcare providers for possible actions to be taken.

Tanioka, et al. [129] recommended the design and direction of development for humanoid nursing robots. In a nonhuman-to-human relationship that is the case for humanoid nursing robots, it is essential to consider what is required from them when it comes to human safety and ethical concerns. If humanoid nursing robots are to interact directly with patients, these robots will be required 
to have the same level of comprehensive judgment ability and responsiveness like that of human nurses that include the ability to deeply observe, quickly respond, judge, and conduct caring with an emphasis on individuality.

\section{Challenges in the Adoption of New Technologies in Older Person Care}

\subsection{The Learning Curve}

Adoption of new healthcare technologies too quickly can result in an increased risk of patient harm [130]. Healthcare professionals have been advised to avoid using new devices without first considering awareness, education, and training needed to ensure safety [131]. There is a need for standardized training programs, rules governing healthcare professionals' credentialing and competence, and guidelines to follow when new technologies become available.

Formal processes should be used to train healthcare professionals in the use of new technologies in healthcare [132]. Additionally, specific credentialing requirements should be adopted by healthcare professionals to ensure that they are properly trained and proficient in the use of a new technology/device. There should be specific policies and procedures in place to evaluate new equipment prior to their purchase and use on patients.

\subsection{The Cost of New Technologies}

A major factor that contributes to the increasing cost of health care is the proliferation of new healthcare technologies which may be new devices. Between $50 \%$ - $75 \%$ of the increase in health care costs every year can be attributed to new developments in healthcare technology [133]. It can be argued that healthcare technologies can increase healthcare costs but new technologies do, on average, improve the quality of health care by improving health outcomes [134]. But innovation does reduce costs. An excellent example is Moore's law where a significant set of technologies are not just improving, but exponentially improving and reducing costs (examples are the use of mobile devices in the diagnosis and management of a host of disease conditions) [135].

\subsection{Security}

An important concern for every healthcare application is security because no security breach is acceptable for the confidential health data of any person. The healthcare industry is still in a rigorous need for cryptographic security that dictates the encryption, transmission, and decryption of data in a secure method [136]. In the creation of a telehealth application that is compliant with various regulations like HIPAA and HL7, a secure encryption algorithm needs to be implemented in order to meet regulated security standards [137].

\subsection{Simpler User Interface}

With new applications approaching the healthcare industry, the user interface 
remains the main point of concern for an application's adoption. A simpler and engaging user interface increases the chances of an application in getting adopted more popularly [138]. People are reluctant to adopt new technologies in the healthcare industry [139]. Therefore, a user-friendly interface is a necessity in healthcare applications [140].

\subsection{Liability Issues}

The mechanical nature of technology makes it impossible to attribute them with liability in cases of malfunctioning or any adverse consequence [141]. Attributing civil and criminal liability will be very complicated. Such liability could theoretically fall on several key persons such as the manufacturer, the programmers, the technicians, or the providers [142]. Such confusion may lead to a deficiency in accountability and may burden the affected person/patient on determining the responsible individual. The issue of liability is even more complicated if artificial intelligence and its application to robots becomes the main issue. One of the main purposes in the provision of artificial intelligence to nursing care robots is to make them autonomous by giving them decision-making abilities [143]. Attributing liability for an adverse event caused by an erroneous decision made by a robot with artificial intelligence could become a legal conundrum.

\subsection{Employment Issues}

Because robots are assured of achieving a high level of efficiency and productivity at a reduced cost when compared with humans, robots can become a very attractive alternative for healthcare providers [144]. As what is happening in almost every other industry, the substitution of humans with robots in the workplace is raising widespread concerns. The reduction of demand in human-provided healthcare services could be a further detriment to a sector that is already in crisis.

\section{Conclusions}

The integration of healthcare technologies into the home leads to concomitant sustainable changes in healthcare. Nurses and nursing practice must take advantage of these technological innovations in healthcare because nursing care provided in a highly technological work environment is the future of nursing practice [145]. The current challenge of future gerontologic nursing is to integrate these technologies into their practice, educational, and research specific aims and competencies. Artificial intelligence cannot truly outperform the agility of the human brain because of the constantly changing, subjective and individually unique nature of healthcare scenarios [146]. Future gerontologic nurses should take advantage of this in order to keep themselves relevant in the healthcare system.

Person-centered care in nursing is guided by the process of 'knowing persons 
as caring' in nursing within the theory of technological competency as caring in nursing [19]. This dynamic process and theory could be implemented at a participative level in a healthcare system that is dominated by technology. Through evidence-based use of technologies, nurses are able to become more familiar with human beings and see them more fully as persons who are active partners in their care rather than merely as an object of care [18]. The focus of nursing would be on knowing the whole person being nursed rather than on fixing the person or replacing a person's missing parts [13].

This paper suggests that nursing care of older persons will be very different in a technologically advanced future. Technology in the future which is here and now enables older persons to live independently, therefore these technologies should consistently progress and change to meet this goal. In the future, which is here and now, older persons will prompt a shift in the methods of healthcare delivery.

Passive reliance on hospitals and healthcare facilities will not be efficient as a viable solution, which is why with technological advancements, home health care is seen as a sustainable system, an alternative to the current institution-based healthcare delivery system. Furthermore, technology would have more roles and functions in the care of older persons, however, nurses would always be critically needed for human interaction, empathy, and autonomy. As long as nurses are willing to grow professionally and transform their practice based on nursing disciplinary perspectives, a better version of extraordinary healthcare practice will develop, thereby assuring that nurses would always have a vital place in the human healthcare arena, particularly in the care of older persons in a technologically advanced future.

\section{Conflicts of Interest}

The authors declare no conflicts of interest regarding the publication of this paper.

\section{References}

[1] WHO (2018) Ageing and Health. https://www.who.int/news-room/fact-sheets/detail/ageing-and-health

[2] Benjamin, R.M. (2010) Multiple Chronic Conditions: A Public Health Challenge. Public Health Reports, 125, 626-627. https://doi.org/10.1177/003335491012500502

[3] Van Der Vorst, A., Zijlstra, G.A.R., De Witte, N., et al. (2016) Limitations in Activities of Daily Living in Community-Dwelling People Aged 75 and Over: A Systematic Literature Review of Risk and Protective Factors. PLoS One, 11, e0165127. https://doi.org/10.1371/journal.pone.0165127

[4] NHS Digital (2016) Hospital Admitted Patient Care Activity, 2016-17. https://digital.nhs.uk/data-and-information/publications/statistical/hospital-admitt ed-patient-care-activity/2016-17

[5] WHO (2018) Density of Nursing and Midwifery Personnel (Total Number per 10000 Population, Latest Available Year).

http://www.who.int/gho/health_workforce/nursing_midwifery_density/en/ 
[6] Institute of Medicine (2009) Supply and Demand in the Health Care Workforce. https://www.ncbi.nlm.nih.gov/books/NBK215247/

[7] Kennedy, R. (2003) The Nursing Shortage and the Role of Technology. Nursing Outlook, 51, S33-S34. https://doi.org/10.1016/S0029-6554(03)00093-9

[8] Wallace, M. (2008) Essentials of Gerontological Nursing. Springer Publishing Company, New York.

http://graduatenursing.medilam.ac.ir/Portals/223/ب/4Meredith_Wallace_Essen tials_of_Gerontological_Nursing_2007.pdf?ver=2016-07-14-202408-320

[9] Kurzweil, R. (1992) The Age of Intelligent Machines. MIT Press, New York, NY.

[10] Thimbleby, H. (2013) Technology and the future of healthcare. Journal of Public Health Research, 2, e28. https://doi.org/10.4081/jphr.2013.e28

[11] Rouleau, G., Gagnon, M.P., Côté, J., Payne-Gagnon, J., Hudson, E. and Dubois, C.A. (2017) Impact of Information and Communication Technologies on Nursing Care: Results of an Overview of Systematic Reviews. Journal of Medical Internet Research, 19, e122. https://doi.org/10.2196/jmir.6686

[12] Funk, M. (2011) As Health Care Technology Advances: Benefits and Risks. American Journal of Critical Care, 20, 285-291. https://doi.org/10.4037/ajcc2011810

[13] Pepito, J.A. and Locsin, R. (2018) Can Nurses Remain Relevant in a Technologically Advanced Future? International Journal of Nursing Sciences, 6, 106-110.

https://doi.org/10.1016/j.ijnss.2018.09.013

[14] Constand, M.K., MacDermid, J.C., Dal Bello-Haas, V. and Law, M. (2014) Scoping Review of Patient-Centered Care Approaches in Healthcare. BMC Health Services Research, 14, 271. https://doi.org/10.1186/1472-6963-14-271

[15] Santana, M.J., Manalili, K., Jolley, R.J., Zelinsky, S., Quan, H. and Lu, M. (2018) How to Practice Person-Centred Care: A Conceptual Framework. Health Expectations, 21, 429-440. https://doi.org/10.1111/hex.12640

[16] Ignatavicius, D.D. and Workman, M.L. (2015) Medical-Surgical Nursing: Patient-Centered Collaborative Care. Elsevier Health Sciences, Amsterdam.

https://books.google.com.ph/books?hl=en\&lr=\&id=zdx2BgAAQBAJ\&oi=fnd\&pg= $\underline{\text { PP1\&dq }=\text { person }+ \text { centered }+ \text { care+ignativicius\&ots }=\text { LLoPcwdNzT\&sig=VjYzAADX3 }}$ g13DxdW6AMSf4J1plU\&redir_esc=y\#v=onepage\&q=person centered care igna$\underline{\text { tivicius } \& \mathrm{f}=\text { false }}$

[17] Boykin, A. and Schoenhofer, S. (2001) Nursing as Caring: A Model for Transforming Practice. Jones and Bartlett Publishers, Boston.

[18] Locsin, R.C. and Purnell, M. (2015) Advancing the Theory of Technological Competency as Caring in Nursing: The Universal Technological Domain. International Journal for Human Caring, 19, 50-54.

[19] Locsin, R.C. (2005) Technological Competency as Caring in Nursing: A Model for Practice. Sigma Theta Tau International Press, Indianapolis, IN. https://cmc.marmot.org/Record/.b35111835

[20] Fozard, J.L., Rietsema, J., Bouma, H. and Graafmans, J.A.M. (2000) Gerontechnology: Creating Enabling Environments for the Challenges and Opportunities of Aging. Educational Gerontology, 26, 331-344. https://doi.org/10.1080/036012700407820

[21] Berwick, D.M., Nolan, T.W. and Whittington, J. (2008) The Triple Aim: Care, Health, And Cost. Health Aff, 27, 759-769.

https://doi.org/10.1377/hlthaff.27.3.759

[22] Kvedar, J., Coye, M.J. and Everett, W. (2014) Connected Health: A Review of 
Technologies and Strategies to Improve Patient Care with Telemedicine and Telehealth. Health Affairs, 33, 194-199. https://doi.org/10.1377/hlthaff.2013.0992

[23] Goodwin, C. (2016) Person-Centered Care: A Definition and Essential Elements. Journal of the American Geriatrics Society, 64, 15-18. https://doi.org/10.1111/jgs.13866

[24] GrandPad (2018) Tablet for Seniors. https://www.grandpad.net/

[25] FaceTime (2019) Facetime Download APP: Android APK, Iphone, \& PC windows. https://ifacetimeapp.com/

[26] Skype (2018) Communication Tool for Free Calls and Chat. https://www.skype.com/en/.

[27] TabSafe (2018) TabSafe-Automatic Medication Pill Dispenser. https://www.tabsafe.com/

[28] Philips (2018) Medication Dispensing Service. Philips Lifeline. https://www.lifeline.philips.com/pill-dispenser/health-mdp.html

[29] Nintendo (2018) Official Site-Wii Fit Plus. http://wiifit.com/

[30] Wellness (2018) Secure Independent Living System from Alarm.com. https://www.alarm.com/productservices/wellness.aspx

[31] BioSensics (2018) ActivePERS-BioSensics. http://www.biosensics.com/solutions/activepers/

[32] Adiant Mobile (2018) GPS Safety Watch | GPS Personal Locator | Alzheimer's and Autism. https://www.adiantmobile.com/

[33] Harris, M.D., Gorski, L. and Narayan, M.C. (2013) Scope and Standards of Home Health Nursing Practice-Why Should You Care? http://www.nahc.org/assets/1/7/am13-501.pdf

[34] Landers, S., Madigan, E., Leff, B., et al. (2016) The Future of Home Health Care: A Strategic Framework for Optimizing Value. Home Health Care Management Practice, 28, 262-278. https://doi.org/10.1177/1084822316666368

[35] Shaughnessy, P.W., Hittle, D.F., Crisler, K.S., et al. (2002) Improving Patient Outcomes of Home Health Care: Findings from Two Demonstration Trials of Outcome-Based Quality Improvement. Journal of the American Geriatrics Society, 50, 1354-1364. https://doi.org/10.1046/j.1532-5415.2002.50356.x

[36] Rosati, R.J. (2015) Home Health Care: Today and Tomorrow. https://www.ncbi.nlm.nih.gov/books/NBK315916/

[37] Han, S.J., Kim, H.K., Storfjell, J. and Kim, M.J. (2013) Clinical Outcomes and Quality of Life of Home Health Care Patients. Asian Nursing Research, 7, 53-60. https://doi.org/10.1016/j.anr.2013.03.002

[38] Madigan, E.A., Gordon, N., Fortinsky, R.H., Koroukian, S.M., Piña, I. and Riggs, J.S. (2012) Predictors of Functional Capacity Changes in a US Population of Medicare Home Health Care (HHC) Patients with Heart Failure (HF). Archives of Gerontology and Geriatrics, 54, e300-e306. https://doi.org/10.1016/j.archger.2011.07.018

[39] Roy, N., Dubé, R., Després, C., Freitas, A. and Légaré, F. (2018) Choosing between Staying at Home or Moving: A Systematic Review of Factors Influencing Housing Decisions among Frail Older Adults. PLoS One, 13, e0189266. https://doi.org/10.1371/journal.pone.0189266

[40] Kruse, C.S., Stein, A., Thomas, H. and Kaur, H. (2018) The Use of Electronic Health Records to Support Population Health: A Systematic Review of the Literature. Journal of Medical Systems, 42, 214. https://doi.org/10.1007/s10916-018-1075-6 
[41] Ventola, C.L. (2014) Mobile Devices and Apps for Health Care Professionals: Uses and Benefits. P\& T: A Peer-Reviewed Journal for Formulary Management, 39, 356-364. http://www.ncbi.nlm.nih.gov/pubmed/24883008

[42] Sorwar, G., Ali, M., Islam, M.K. and Miah, M.S. (2016) An Integrated Patient Information and In-Home Health Monitoring System Using Smartphones and Web Services. Studies in Health Technology and Informatics, 231, 119-126.

http://www.ncbi.nlm.nih.gov/pubmed/27782023

[43] Demiris, G. (2015) Innovations in Technology. https://www.ncbi.nlm.nih.gov/books/NBK315926/

[44] McLean, S., Sheikh, A., Cresswell, K., et al. (2013) The Impact of Telehealthcare on the Quality and Safety of Care: A Systematic Overview. PLoS One., 8, e71238. https://doi.org/10.1371/journal.pone.0071238

[45] Vegesna, A., Tran, M., Angelaccio, M. and Arcona, S. (2017) Remote Patient Monitoring via Non-Invasive Digital Technologies: A Systematic Review. Telemedicine and E-Health, 23, 3-17. https://doi.org/10.1089/tmj.2016.0051

[46] Tao, H. and McRoy, S. (2015) Caring for and Keeping the Elderly in Their Homes. Chinese Nursing Research, 2, 31-34. https://doi.org/10.1016/j.cnre.2015.08.002

[47] Dinesen, B., Nonnecke, B., Lindeman, D., et al. (2016) Personalized Telehealth in the Future: A Global Research Agenda. Journal of Medical Internet Research, 18, e53. https://doi.org/10.2196/jmir.5257

[48] Gensini, G.F., Alderighi, C., Rasoini, R., Mazzanti, M. and Casolo, G. (2017) Value of Telemonitoring and Telemedicine in Heart Failure Management. Cardiac Failure Review, 3, 116-121. https://doi.org/10.15420/cfr.2017:6:2

[49] Faruque, L.I., Wiebe, N., Ehteshami-Afshar, A., et al. (2017) Effect of Telemedicine on Glycated Hemoglobin in Diabetes: A Systematic Review and Meta-Analysis of Randomized Trials. CMAJ, 189, E341-E364. https://doi.org/10.1503/cmaj.150885

[50] Sanner, T. (2004) Using Telehealth to Address the Nursing Shortage. Home Healthc Nurse, 22, 695-699. http://www.ncbi.nlm.nih.gov/pubmed/15486507

[51] Joe, J. and Demiris, G. (2013) Older Adults and Mobile Phones for Health: A Review. Journal of Biomedical Informatics, 46, 947-954. https://doi.org/10.1016/j.jbi.2013.06.008

[52] Whitehead, L. and Seaton, P. (2016) The Effectiveness of Self-Management Mobile Phone and Tablet Apps in Long-term Condition Management: A Systematic Review. Journal of Medical Internet Research, 18, e97. https://doi.org/10.2196/jmir.4883

[53] GeriatricsCareOnline.org (2018) IGeriatrics-Mobile App: Aimed at Healthcare Providers and Covering a Wide Range of Topics Relating to Older Adults, from Medication Safety to Cross-Cultural Assistance.

https://geriatricscareonline.org/ProductAbstract/igeriatrics-mobile-app/B019

[54] Ebling Library (2012) Spotlight on Thomson Micromedex-MICROMEDEX. https://ebling.library.wisc.edu/spotlight/micromedex.php

[55] Medscape (2018) Medscape App. https://www.medscape.com/public/medscapeapp

[56] MIMS (2018) MIMS Mobile App. https://www.mims.com/mobile-app

[57] Lexicomp (2018) Lexicomp Drug Information Apps | Clinical Drug Information. https://www.wolterskluwercdi.com/drug-reference/apps/

[58] Epocrates (2018) Point of Care Medical Applications. https://www.epocrates.com/

[59] Unitron (2018) Download UHear Mobile App. 
http://unitron.com/content/unitron/sg/en/consumer/your-hearing/self-assessment/ download-uhear-mobile-app.html

[60] HearX Group (2018) HearX Group-HearScreen. https://www.hearxgroup.com/hearscreen/

[61] AngelSense (2018) AngelSense GPS \& Phone for Dementia \& Alzheimer's. https://www.angelsense.com/protect/dementia/

[62] Bioinformatics Research Group (2018) Dementia Screener-Apps on Google Play. https://play.google.com/store/apps/details?id=appinventor.ai_lcchien86.DementiaS creener\&hl=en_US

[63] Connected Neurosciences LLC (2018) Parkinson's LifeKit. https://itunes.apple.com/us/app/parkinsons-lifekit/id1226151783? $\mathrm{mt}=8$

[64] MyTherapy (2018) The Symptom Tracker App for Parkinson's Disease. https://www.mytherapyapp.com/parkinsons-disease-app

[65] Dimitrov, D.V. (2016) Medical Internet of Things and Big Data in Healthcare. Healthcare Informatics Research, 22, 156-163. https://doi.org/10.4258/hir.2016.22.3.156

[66] Furness, A. (2008) A Framework Model for the Internet of Things. GRIFS/CASAGRAS, Hong Kong, China.

[67] International Telecommunication Union (ITU) (2005) Internet Reports 2005: The Internet of Things. https://www.itu.int/net/wsis/tunis/newsroom/stats/The-Internet-of-Things-2005.pd $\mathrm{f}$

[68] Information Society and Media (INFSO) (2008) Internet of Things in 2020: A Roadmap for the Future.

http://www.mckinsey.com/business-functions/business-technology/our-insights/big -data-the-next-frontier-for-innovation

[69] De Saint-Exupery, A. (2009) Internet of Things, Strategic Research Roadmap. European Commission Social Media, Brussels, Belgium.

[70] Majumder, S., Aghayi, E., Noferesti, M., et al. (2017) Smart Homes for Elderly Healthcare-Recent Advances and Research Challenges. Sensors, 17, 2496. https://doi.org/10.3390/s17112496

[71] Demonceau, J., Ruppar, T., Kristanto, P., et al. (2013) Identification and Assessment of Adherence-Enhancing Interventions in Studies Assessing Medication Adherence through Electronically Compiled Drug Dosing Histories: A Systematic Literature Review and Meta-Analysis. Drugs, 73, 545-562.

https://doi.org/10.1007/s40265-013-0041-3

[72] Treskes, R.W., Van der Velde, E.T., Schoones, J.W. and Schalij, M.J. (2018) Implementation of Smart Technology to Improve Medication Adherence in Patients with Cardiovascular Disease: Is It Effective? Expert Review of Medical Devices, 15, 119-126. https://doi.org/10.1080/17434440.2018.1421456

[73] Evalan (2018) Improve Adherence with IoT Application. https://evalan.com/en/projects/improve-adherence/

[74] Pak, J. and Park, K. (2012) Construction of a Smart Medication Dispenser with High Degree of Scalability and Remote Manageability. Journal of Biomedicine and Biotechnology, 2012, Article ID: 381493. https://doi.org/10.1155/2012/381493

[75] Haghi, M., Thurow, K. and Stoll, R. (2017) Wearable Devices in Medical Internet of Things: Scientific Research and Commercially Available Devices. Healthcare Informatics Research, 23, 4-15. https://doi.org/10.4258/hir.2017.23.1.4 
[76] Bayo-Monton, J.-L., Martinez-Millana, A., Han, W., Fernandez-Llatas, C., Sun, Y. and Traver, V. (2018) Wearable Sensors Integrated with Internet of Things for Advancing EHealth Care. Sensors, 18, 1851. https://doi.org/10.3390/s18061851

[77] Darkins, A., Kendall, S., Edmonson, E., Young, M. and Stressel, P. (2015) Reduced Cost and Mortality Using Home Telehealth to Promote Self-Management of Complex Chronic Conditions: A Retrospective Matched Cohort Study of 4,999 Veteran Patients. Telemedicine and E-Health, 21, 70-76. https://doi.org/10.1089/tmj.2014.0067

[78] Ni, Q., García-Hernando, A.B. and De la Cruz, I.P. (2015) The Elderly's Independent Living in Smart Homes: A Characterization of Activities and Sensing Infrastructure Survey to Facilitate Services Development. Sensors, 15, 11312-11362. https://doi.org/10.3390/s150511312

[79] Van Hoof, J., Demiris, G. and Wouters, E. (2017) Handbook of Smart Homes, Health Care and Well-Being. Springer International Publishing, Switzerland. https://doi.org/10.1007/978-3-319-01904-8

[80] Bellazzi, R. (2014) Big Data and Biomedical Informatics: A Challenging Opportunity. Yearbook of Medical Informatics, 23, 8-13. https://doi.org/10.15265/IY-2014-0024

[81] Lavecchia, A. (2015) Machine-Learning Approaches in Drug Discovery: Methods and Applications. Drug Discovery Today, 20, 318-331. https://doi.org/10.1016/j.drudis.2014.10.012

[82] Rumsfeld, J.S., Joynt, K.E. and Maddox, T.M. (2016) Big Data Analytics to Improve Cardiovascular Care: Promise and Challenges. Nature Reviews Cardiology, 13, 350-359. https://doi.org/10.1038/nrcardio.2016.42

[83] Roski, J., Bo-Linn, G.W. and Andrews, T.A. (2014) Creating Value in Health Care through Big Data: Opportunities and Policy Implications. Health Affairs, 33, 1115-1122. https://doi.org/10.1377/hlthaff.2014.0147

[84] El Aboudi, N. and Benhlima, L. (2018) Big Data Management for Healthcare Systems: Architecture, Requirements, and Implementation. Advances in Bioinformatics, 2018, Article ID: 4059018. https://doi.org/10.1155/2018/4059018

[85] Norton, S.P., Dickerson, E.M., Kulwin, C.G. and Shah, M.V. (2017) Technology that Achieves the Triple Aim: An Economic Analysis of the BrainPath Approach in Neurosurgery. ClinicoEconomics and Outcomes Research, 9, 519-523. https://doi.org/10.2147/CEOR.S133623

[86] Lee, S.-K., Son, Y.-J., Kim, J., et al. (2014) Prediction Model for Health-Related Quality of Life of Elderly with Chronic Diseases using Machine Learning Techniques. Healthcare Informatics Research, 20, 125-134. https://doi.org/10.4258/hir.2014.20.2.125

[87] Kang, M., Park, E., Cho, B.H. and Lee, K.-S. (2018) Recent Patient Health Monitoring Platforms Incorporating Internet of Things-Enabled Smart Devices. International Neurourology Journal, 22, S76-S82. https://doi.org/10.5213/inj.1836144.072

[88] Evangelista, L.S., Lee, J.-A., Moore, A.A., et al. (2015) Examining the Effects of Remote Monitoring Systems on Activation, self-Care, and Quality of Life in Older Patients with Chronic Heart Failure. Journal of Cardiovascular Nursing, 30, 51-57.

[89] Beuscher, L.M., Fan, J., Sarkar, N., Dietrich, M.S., Newhouse, P.A., Miller, K.F. and Mion, L.C. (2017) Socially Assistive Robots: Measuring Older Adults' Perceptions. Journal of Gerontological Nursing, 43, 35-43. https://doi.org/10.3928/00989134-20170707-04

[90] Breazeal, C. (2011) Social Robots for Health Applications. 2011 Annual Interna- 
tional Conference of the IEEE Engineering in Medicine and Biology Society, Boston, MA, 30 August-3 September 2011, 5368-5371.

https://doi.org/10.1109/IEMBS.2011.6091328

[91] Cresswell, K., Cunningham-Burley, S. and Sheikh, A. (2018) Health Care Robotics: Qualitative Exploration of Key Challenges and Future Directions. Journal of Medical Internet Research, 20, e10410. https://doi.org/10.2196/10410

[92] Loh, E. (2018) Medicine and the Rise of the Robots: A Qualitative Review of Recent Advances of Artificial Intelligence in Health. BMJ Leader, 2, 59-63.

https://doi.org/10.1136/leader-2018-000071

[93] Hassmiller, S.B. and Cozine, M. (2006) Addressing the Nurse Shortage to Improve the Quality of Patient Care. Health Affairs, 25, 268-274.

https://doi.org/10.1377/hlthaff.25.1.268

[94] Alaiad, A. and Zhou, L. (2014) The Determinants of Home Healthcare Robots Adoption: An Empirical investigation. International Journal of Medical Informatics, 83, 825-840. https://doi.org/10.1016/j.ijmedinf.2014.07.003

[95] Bayer, E. (2010) Innovations in Reducing Preventable Hospital Admissions, Readmissions, and Emergency Room Use. AHIP Center for Policy and Research, America. https://books.google.com.ph/books/about/Innovations_in_Reducing_Preventable_ Hosp.html?id=1lXWYgEACAAJ\&redir_esc $=$ y

[96] Coughlin, J.F., Pope, J.E. and Leedle, B.R. (2006) Old Age, New Technology, and Future Innovations in Disease Management and Home Health Care. Home Health Care Management and Practice, 18, 196-207. https://doi.org/10.1177/1084822305281955

[97] Abdi, J., Al-Hindawi, A., Ng, T. and Vizcaychipi, M.P. (2018) Scoping Review on the Use of Socially Assistive Robot Technology in Elderly Care. BMJ Open, 8, e018815. https://doi.org/10.1136/bmjopen-2017-018815

[98] Birks, M., Bodak, M., Barlas, J., Harwood, J. and Pether, M. (2016) Robotic Seals as Therapeutic Tools in an Aged Care Facility: A Qualitative Study. Journal of Aging Research, 2016, Article ID: 8569602. https://doi.org/10.1155/2016/8569602

[99] Goher, K.M., Mansouri, N. and Fadlallah, S.O. (2017) Assessment of Personal Care and Medical Robots from Older Adults' Perspective. Robotics and Biomimetics, 4, 5. https://doi.org/10.1186/s40638-017-0061-7

[100] Łukasik, S., Tobi, S., Wieczorowska-Tobis, K. and Suwalska, A. (2018) Could Robots Help Older People with Age-Related Nutritional Problems? Opinions of Potential Users. The International Journal of Environmental Research and Public Health, 15, 2535. https://doi.org/10.3390/ijerph15112535

[101] Mitzner, T.L., Chen, T.L., Kemp, C.C. and Rogers, W.A. (2014) Identifying the Potential for Robotics to Assist Older Adults in Different Living Environments. International Journal of Social Robotics, 6, 213-227. https://doi.org/10.1007/s12369-013-0218-7

[102] Byford, S. (2015) This Cuddly Japanese Robot Bear Could Be the Future of Elderly care. The Verge.

https://www.theverge.com/2015/4/28/8507049/robear-robot-bear-japan-elderly

[103] Johnstone, T. (2017) Robots to the Rescue in Elderly Care. Seniors News. https://www.seniorsnews.com.au/news/robots-to-the-rescue-in-elderly-care/313838 $\underline{31}$

[104] Pasick, A. (2014) Softbank's Humanoid Robot will Be Great for Tending to Japan’s elderly. Quartz.

https://qz.com/217199/softbanks-humanoid-robot-will-be-great-for-tending-to-jap 
ans-elderly/

[105] Kittman, R., Fröhlich, T., Schäfer, J., Reiser, U., Weisshardt, F. and Haug, A. (2015) Let me Introduce Myself: I am Care-O-Bot 4, a Gentleman Robot. In: Diefenbach, S., Henze, N. and Pielot, M., Eds., Mensch und Computer 2015 Tagungsband, Stuttgart: Oldenbourg Wissenschaftsverlag, 223-232.

https://www.researchgate.net/publication/281967530_Let_me_Introduce_Myself_I_ am_Care-O-bot_4_a_Gentleman_Robot

[106] Muoio, D. (2015) Japan Developing Carebots for Elderly Care. Business Insider. https://www.businessinsider.com/japan-developing-carebots-for-elderly-care-2015$\underline{11}$

[107] Obringer, L.A. and Strickland, J. (2018) How ASIMO Works. How Stuff Works. https://science.howstuffworks.com/asimo.htm

[108] AARP International (2017) Dinsow. https://www.aarpinternational.org/resources/global-innovations/dinsow

[109] Haselton, T. (2018) Elliq Robot for Elderly First Look. https://www.cnbc.com/2018/01/09/elliq-robot-for-elderly-first-look.html

[110] Tarantola, A. (2017) Robot Caregivers Are Saving the Elderly from Lives of Loneliness.

https://www.engadget.com/2017/08/29/robot-caregivers-are-saving-the-elderly-fro $\underline{\text { m-lives-of-loneliness/ }}$

[111] Collins, E.C., Prescott, T.J., Mitchinson, B. and Conran, S. (2015) MIRO: A Versatile Biomimetic Edutainment Robot. Proceedings of the 12th International Conference on Advances in Computer Entertainment Technology, Iskandar, Malaysia, 16-19 November 2015. https://doi.org/10.1145/2832932.2832978

[112] Consequential Robotics (2018) MiRo-Consequential Robotics. http://consequentialrobotics.com/miro/

[113] Dorhmehl, L. (2017) MiRo Is A Robot Dog That Recognizes Faces, Cares For Old Folks. Digital Trends. https://www.digitaltrends.com/cool-tech/miro-robot-dog-elderly-care/

[114] Kavanagh, M. (2017) Meet MiRo the Robotic Dog. Buzz.ie. https://www.buzz.ie/gadgets/meet-miro-the-robotic-dog-262138

[115] Intelligent System Research Institute (2018) PARO Therapeutic Robot. http://www.parorobots.com/contact.asp

[116] Intelligent Systems Co. (2018) PARO Therapeutic Robot. http://www.parorobots.com/

[117] Yu, R., Hui, E., Lee, J., et al. (2015) Use of a Therapeutic, Socially Assistive Pet Robot (PARO) in Improving Mood and Stimulating Social Interaction and Communication for People With Dementia: Study Protocol for a Randomized Controlled Trial. JMIR Research Protocols, 4, e45. https://doi.org/10.2196/resprot.4189

[118] Business Wire (2014) Panasonic's Robotic Technology Helps Deliver "A Better Life" to the World of Welfare.

https://www.businesswire.com/news/home/20141003005229/en/Panasonics-Roboti c-Technology-Helps-Deliver-Life-World

[119] Panasonic (2018) “Resyone Plus” Robotic Care Bed/Wheelchair. https://www.panasonic.oa.hk/english/products/age-free-product/resyone-plus/xpns10601hk.aspx

[120] Reif Co. Ltd. (2018) Assist Robot for Walking Rehabilitation, TREE. New Value Creation NAVI, New Value Creation PORTAL. 
https://shinkachi-portal.smrj.go.jp/en/navi/company/p1tvk/t3lep/

[121] Robotics Today (2015) Personal Robots Group at MIT Media Lab. Robot | Jibo | Description. https://www.roboticstoday.com/robots/jibo-description

[122] D’Arcy, C. (2017) “A Cute Little Fecker”: Trinity’s Stevie the Robot Helps Older People.

https://www.irishtimes.com/business/technology/a-cute-little-fecker-trinity-s-stevie -the-robot-helps-older-people-1.3290009

[123] Blue Frog Robotics (2018) BUDDY. The Emotional Robot. https://buddytherobot.com/en/buddy-the-emotional-robot/

[124] Ackerman, E. (2018) Moxi Prototype from Diligent Robotics Starts Helping Out in Hospitals. IEEE Spectrum.

https://spectrum.ieee.org/automaton/robotics/industrial-robots/moxi-prototype-fro m-diligent-robotics-starts-helping-out-in-hospitals

[125] Johnson, K. (2018) Moxi Is a Hospital Robot with Social Intelligence. https://venturebeat.com/2018/09/18/moxi-is-a-hospital-robot-with-social-intelligen ce/

[126] Pearce, A.J., Adair, B., Miller, K., et al. (2012) Robotics to Enable Older Adults to Remain Living at Home. Journal of Aging Research, 2012, Article ID: 538169. https://doi.org/10.1155/2012/538169

[127] Warren, H. and Dasgupta, P. (2009) The Future of Robotics. IEEE Robotics \& Automation Magazine, 16, 19-22. https://doi.org/10.1109/MRA.2008.931643

[128] Korchut, A., Szklener, S., Abdelnour, C., et al. (2017) Challenges for Service Robots-Requirements of Elderly Adults with Cognitive Impairments. Frontiers in Neurology, 228. https://doi.org/10.3389/fneur.2017.00228

[129] Tanioka, T., Osaka, K., Locsin, R., Yasuhara, Y. and Ito, H. (2017) Recommended Design and Direction of Development for Humanoid Nursing Robots Perspective from Nursing Researchers. Intelligent Control and Automation, 8, 96-110. https://doi.org/10.4236/ica.2017.82008

[130] Powell-Cope, G., Nelson, A.L. and Patterson, E.S. (2008) Patient Care Technology and Safety. Patient Safety and Quality: An Evidence-Based Handbook for Nurses. Agency for Healthcare Research and Quality (US). http://www.ncbi.nlm.nih.gov/pubmed/21328784

[131] Otero, P., Hersh, W. and Jai-Ganesh, A.U. (2014) Big Data: Are Biomedical and Health Informatics Training Programs Ready? Contribution of the IMIA Working Group for Health and Medical Informatics Education. Yearbook of Medical Informatics, 9, 177-181. https://doi.org/10.15265/IY-2014-0007

[132] Cuff, P.A. and Forstag, E.H. (2018) Improving Health Professional Education and Practice through Technology. Proceedings of a Workshop. The National Academies Press, Washington, DC. https://doi.org/10.17226/25072

[133] Sorenson, C., Drummond, M. and Bhuiyan-Khan, B. (2013) Medical Technology as a Key Driver of Rising Health Expenditure: Disentangling the Relationship. ClinicoEconomics and Outcomes Research: CEOR, 5, 223-234. https://doi.org/10.2147/CEOR.S39634

[134] Gelijns, A.C. and Halm, E.A. (1991) The Diffusion of New Technology: Costs and Benefits to Health Care. https://www.ncbi.nlm.nih.gov/books/NBK234309/

[135] Dzau, V.J., Asch, D.A., Hannaford, B., Aggarwal, R. and Pugh, C.M. (2017) Debate on the cost of innovation in healthcare: Is It Too Costly? BMJ Simulation and 
Technology Enhanced Learning, 3, S33-S36.

https://doi.org/10.1136/bmjstel-2016-000174

[136] Jalali, M.S., Razak, S., Gordon, W., Perakslis, E. and Madnick, S. (2019) Health Care and Cybersecurity: Bibliometric Analysis of the Literature. Journal of Medical Internet Research, 21, e12644. https://doi.org/10.2196/12644

[137] Anthony, D., Campbell, A.T., Candon, T., Gettinger, A., Kotz, D., Marsch, L.A., et al. (2013) Securing Information Technology in Healthcare. IEEE Security \& Privacy, 11, 25-33. https://doi.org/10.1109/MSP.2013.104

[138] Mosa, A.S.M., Yoo, I. and Sheets, L. (2012) A Systematic Review of Healthcare Applications for Smartphones. BMC Medical Informatics and Decision Making, 12, 67. https://doi.org/10.1186/1472-6947-12-67

[139] Safi, S., Thiessen, T. and Schmailzl, K.J. (2018) Acceptance and Resistance of New Digital Technologies in Medicine: Qualitative Study. JMIR Research Protocols, 7, e11072. https://doi.org/10.2196/11072

[140] Van Velthoven, M.H., Smith, J., Wells, G. and Brindley, D. (2018) Digital Health App Development Standards: A Systematic Review Protocol. BMJ Open, 8, e022969. https://doi.org/10.1136/bmjopen-2018-022969

[141] White, D. (1986) The Impact of Computer Technology on Tort Liability of Doctors and Hospitals. Health Law in Canada, 7, 6-13. http://www.ncbi.nlm.nih.gov/pubmed/10312106

[142] Poirot-Mazères, I. (2013) Robotics and Medical Technology: Which Liability? Journal International de Bioethique (International Journal of Bioethics), 24, 99-124. http://www.ncbi.nlm.nih.gov/pubmed/24558739 https://doi.org/10.3917/jib.243.0099

[143] Kim, J. (2018) Use of Robots as a Creative Approach in Healthcare ICT. Healthcare Informatics Research, 24, 155-156. https://doi.org/10.4258/hir.2018.24.3.155

[144] Senior, T. (2016) Being Replaced by a Robot. The British Journal of General Practice, 66, 436. https://doi.org/10.3399/bjgp16X686461

[145] De Momi, E., Kranendonk, L., Valenti, M., Enayati, N. and Ferrigno, G. (2016) A Neural Network-Based Approach for Trajectory Planning in Robot-Human Handover Tasks. Frontiers in Robotics AI, 3, 34. https://doi.org/10.3389/frobt.2016.00034

[146] Panch, T., Szolovits, P. and Atun, R. (2018) Artificial Intelligence, Machine Learning and Health Systems. Journal of Global Health, 8, Article ID: 020303. https://doi.org/10.7189/jogh.08.020303 